\title{
Beige adipocytes contribute to breast cancer progression
}

\author{
MARIANA GANTOV ${ }^{1}$, PRISCILA PAGNOTTA ${ }^{1,2}$, CECILIA LOTUFO ${ }^{1}$, GUSTAVO MARCELO RINDONE ${ }^{3}$, \\ MARIA FERNANDA RIERA ${ }^{3}$, JUAN CARLOS CALVO ${ }^{1,2}$ and JUDITH TONEATTO ${ }^{1}$
}

\author{
${ }^{1}$ Institute of Biology and Experimental Medicine (IBYME), CONICET, Buenos Aires C1428; \\ ${ }^{2}$ Department of Biological Chemistry, Faculty of Exact and Natural Sciences, University of Buenos Aires, Buenos Aires C1428; \\ ${ }^{3}$ Endocrinological Research Center 'Dr César Bergada' (CEDIE), CONICET, Children's Endocrinology Foundation (FEI), \\ Division of Endocrinology, Children's Hospital ‘Dr Ricardo Gutiérrez' of Buenos Aires, Buenos Aires C1425, Argentina
}

Received May 16, 2020; Accepted September 28, 2020

DOI: $10.3892 /$ or.2020.7826

\begin{abstract}
Adipocytes are the main stromal cells in the mammary microenvironment, and crosstalk between adipocytes and breast cancer cells may play a critical and important role in cancer maintenance and progression. Tumor-induced differentiation to beige/brown adipose tissue is an important contribution to the hypermetabolic state of breast cancer. However, the effect of epithelial cell-beige adipocyte communication on tumor progression remains unclear. To contribute to the understanding of this phenomenon, we characterized components present in conditioned media $(\mathrm{CM})$ from beige
\end{abstract}

Correspondence to: Dr Judith Toneatto, Institute of Biology and Experimental Medicine (IBYME), CONICET, Vuelta de Obligado 2490, CABA, Buenos Aires C1428, Argentina E-mail: jtoneatto@dna.uba.ar

Abbreviations: ATP, adenosine triphosphate; BA, beige adipocyte; BAT, brown adipose tissue; BSA, bovine serum albumin; CAAs, cancer-associated adipocytes; CM, conditioned media; CIDEA, cell death-inducing DFFA-like effector A; Ctrol, control; DEPSGs, differentially expressed predicted secreted genes; D-MEM/F-12, Dulbecco's modified Eagle's medium/Nutrient Mixture F12; ECM, extracellular matrix; EMT, epithelial mesenchymal transition; ER, estrogen receptor; FABP4, fatty acid binding protein 4; FBS, fetal bovine serum; GLUT4, glucose transporter 4; HER2, human epidermal growth factor receptor 2; HSL, hormone-sensitive lipase; HRP, horseradish peroxidase; IBMX, 3-isobutyl-1-methylxanthine; IIF, indirect immunofluorescence; LD, lipid droplet; LDH, lactate dehydrogenase; MCTs, monocarboxylate transporters; MMPs, matrix metalloproteases; N, nuclei; ObR, leptin receptor; ON, overnight; PBS, phosphate-buffered saline; PET/CT, positron emission tomography/computerized tomography; Pgcl $\alpha$, peroxisome proliferator activated receptor- $\gamma$ coactivator $1-\alpha$; PPAR $\gamma$, peroxisome proliferator-activated receptor gamma; $\mathrm{PR}$, progesterone receptor; PVDF, polyvinylidene fluoride; RT, room temperature; TCA, tricarboxylic acid; TGs, triglycerides; TZDs, thiazolidinediones; UCP1, uncoupled protein 1; WA, white adipocyte; WAT, white adipose tissue

Key words: white adipocytes, beige adipocytes, breast cancer, tumor progression, tumor microenvironment, soluble factors adipocytes (BAs) or white adipocytes (WAs), and evaluated the effects of BA- and WA-CM on both adhesion and migration of tumor (LM3, 4T1 and MC4-L1) and non-tumor (NMuMG) mouse mammary epithelial cell lines. Additionally, we analyzed the expression of ObR, CD44, vimentin, MMP-9, MCT1 and LDH in tumor and non-tumor mouse mammary epithelial cell lines incubated with BA-CM, WA-CM or Ctrol-CM (control conditioned media). 3T3-L1 preadipocytes differentiated into beige adipocytes upon PPAR $\gamma$ activation (rosiglitazone) displaying characteristics that morphologically resembled brown/beige adipocytes. Levels of UCP1, CIDEA, GLUT4, leptin, MCT4 and FABP4 were increased, while adiponectin, caveolin 1 and perilipin 1 levels were decreased in BAs with respect to WAs. Tumor cell lines revealed lower cell adhesion and increased cell migration after incubation with BA- and WA-CM vs. Ctrol-CM. ObR and MMP-9 in MC4-L1 cells were significantly increased after incubation with BA-CM vs. WA- and Ctrol-CM. In addition, MC4-L1 and LM3 cells significantly increased their migration in the presence of BAs, suggesting that new signals originating from the crosstalk between BAs and tumor cells, could be responsible for this change. Our results indicate that beige adipocytes are able to regulate the behavior of both tumor and non-tumor mouse mammary epithelial cells, favoring tumor progression.

\section{Introduction}

Tumor progression depends on the influence of not only tumor cells but also surrounding stromal tissue (1), where adipocytes are the main cellular component and thus constitute the main part of the breast cancer microenvironment. After interacting with breast cancer cells, adipocytes are converted into cancer-associated adipocytes (CAAs) and, as such, promote tumor progression (2-4). There is emerging evidence indicating that adipocytes enhance tumor progression by mutual and dynamic cross-communication with tumor cells (5). Adipocytes, as well-known endocrine cells, produce several inflammatory factors, growth factors and cytokines which, in turn, stimulate receptor tyrosine kinase downstream signaling and programs for epithelial mesenchymal transition (EMT) (6,7). Specifically, tumors may turn a normal stroma into an advantageous microenvironment by different means, 
such as promoting a wound healing response or the metabolic reprogramming of adipocytes $(8,9)$.

From a histological and functional point of view, two types of adipose tissue have been distinguished, white and brown (10). White adipose tissue (WAT) is composed of cells specialized to store excess energy, as evidenced by the presence of one large lipid droplet (LD) (unilocular adipocyte) filled up with triglycerides (TGs), and characterized by an extremely low oxidative capacity, as a consequence of a small number of thin and elongated mitochondria (11). In contrast, brown adipose tissue (BAT) converts excess energy into heat through uncoupled respiration depending, in part, on the expression of uncoupling protein 1 (UCP1) $(10,12)$. WAT does not normally express UCP1; nevertheless, clusters of UCP1-expressing adipocytes (named beige or 'brite', as in brown in white) with thermogenic capacity develop within WAT in response to various stimuli (13). Beige adipocytes within WAT are defined by the morphology of the multilocular and small lipid droplets, a high mitochondrial content and the expression of a set of brown fat-specific genes [for example, Ucpl, Cidea (cell death-inducing DFFA-like effector A) and Pgcl $\alpha$ (peroxisome proliferator activated receptor- $\gamma$ coactivator $1-\alpha)$ ].

In the breast, WAT is present continuously from birth to adulthood, whereas BAT often has a temporary appearance $(14,15)$. Knowledge of the contribution of brown/beige adipose cells to mammary gland physiology and how its temporary appearance is regulated is rather limited.

Recent studies have associated brown adipocytes with breast cancer (16-19). BAT secretes diverse soluble factors, ('batokines'), expresses high levels of glucose transporter 4 (GLUT4) and consumes higher levels of glucose (20). Using ${ }^{18} \mathrm{~F}$-labeled fluorodeoxyglucose positron emission tomography/computerized tomography (PET/CT), a high prevalence of BAT activity was found in breast cancer patients when compared to a weight-matched cohort of patients with other solid tumor malignancies (16). Additionally, a persistent deposition of brown adipose cells has been observed in the mammary glands of BRCA1-mutant mice (17) and a higher browning of mammary fat has been reported close to malignant tumors compared to the vicinity of benign breast lesions $(19,21)$. Wu et al postulated that the preliminary step towards a tumor-adipocyte crosstalk is the ability of tumor cells to induce beige/brown differentiation as well as a lipolytic process in adipocytes (19). In this context, the question arises as to whether beige adipocytes could be new and key actors in breast cancer development and maintenance of a cancerous phenotype. In other words, can beige adipocytes indeed modify the behavior of epithelial breast cancer cells?

Herein, we attempted to determine the effects of brown/beige adipose cells on adhesion and migration, key processes in tumor progression. For this purpose, 3T3-L1 adipocytes differentiated in the presence of rosiglitazone, a strong inducer of white to brown fat conversion, were used as a model of murine beige adipocytes. Soluble and non-soluble components present in beige adipocytes (BAs), were identified and compared with those present in white adipocytes (WAs) by indirect immunofluorescence, RT-qPCR and western blot analysis. The effect of soluble factors released by WAs and BAs on adhesion and migration of NMuMG (non-tumor) and LM3, 4T1 and MC4-L1 (tumor) mouse mammary epithelial cell lines was studied using WA- or BA-conditioned media (CM). Factors whose levels are modified in mammary cell lines (non-tumor and tumor) following incubation with BA- or WA-CM for $24 \mathrm{~h}$ were evaluated; particularly leptin receptor (ObR), CD44, vimentin and matrix metalloprotease (MMP)-9 (tumor progression markers in epithelial cells) and monocarboxylate transporter (MCT)1 and lactate dehydrogenase (LDH) (metabolic markers).

The present study provides significant evidence that BAs could promote breast cancer progression in a murine in vitro model. However, the physiological importance of beige adipose cells in tumor microenvironment and the regulation of breast cancer cell behavior, remain open questions.

\section{Materials and methods}

Reagents. Culture medium Dulbecco's modified Eagle's medium/Nutrient Mixture F12 D-MEM/F-12 (cat. no. 12400-024), trypsin-EDTA (cat. no. 25200-072) were purchased from Gibco (Thermo Fisher Scientific, Inc.); phenol red-free D-MEM/F-12 (cat. no. 90-090-PBR) was obtained from Corning (Mediatech, Inc.); heat-inactivated fetal bovine serum (FBS) from Natocor; 3-isobutyl-1-methylxanthine (IBMX, cat. no. I7018), bovine serum albumin (BSA, cat. no. 10735086001) and dexamethasone (cat. no. D1756) were purchased from Sigma-Aldrich/Merck KGaA and rosiglitazone (cat. no. ab120762) was from Abcam.

Culture of tumor and non-tumor mammary cancer cells. Immortalized epithelial cell lines, derived from tumor (4T1, LM3 and MC4-L1) and non-tumor (NMuMG) mammary cells were used. Mouse metastatic mammary cancer cells 4T1 (ER$\mathrm{PR}^{-}, \mathrm{HER} 2^{-}$) and NMuMG were obtained from the American Type Culture Collection (ATCC). LM3 is an immortalized mouse metastatic mammary cell line obtained from a primary tumor (ER', $\left.\mathrm{PR}^{-}, \mathrm{HER}^{+}\right)$by Urtreger et al (22). MC4-L1 is an immortalized mouse metastatic mammary line obtained from a primary tumor $\left(\mathrm{ER}^{+}, \mathrm{PR}^{+}\right)$by Lanari et al (23). All cells were cultured in D-MEM/F-12 medium (cat. no. 12400-024; Gibco; Thermo Fisher Scientific, Inc.) containing 10\% FBS (complete D-MEM/F-12 medium) in a humidified $5 \% \mathrm{CO}_{2}$ atmosphere at $37^{\circ} \mathrm{C}$. Every $2-3$ days, cell culture medium was removed and replaced by complete D-MEM/F-12 medium. All cells used were mycoplasma-free.

Culture and differentiation of preadipocytes 3T3-L1. Murine 3T3-L1 preadipocyte cells (obtained from ATCC) were grown in complete D-MEM/F-12 medium in a humidified $5 \% \mathrm{CO}_{2}$ atmosphere at $37^{\circ} \mathrm{C}$. Cells were used between passages 12-22; adipocyte differentiation was induced as previously described (24). Briefly, 3T3-L1 preadipocytes were seeded in 12-well plates and grown until confluence (day 0). Two days later, an adipogenic cocktail containing $0.5 \mathrm{mM}$ IBMX, $0.1 \mu \mathrm{M}$ dexamethasone and $0.1 \mu \mathrm{M}$ rosiglitazone was added and cells were cultured further for 2 days. Subsequently, culture medium was replaced by complete D-MEM/F-12 containing $2 \mu \mathrm{M}$ insulin until the end of the culture period, changing the medium every other day. After 9-10 days, 90-100\% cells had differentiated into WAs, with increasing TG content and formation of LDs, which were visualized under light 
microscopy either directly or following Oil Red O staining. To obtain BAs, 3T3-L1 preadipocytes were differentiated in the presence of $1 \mu \mathrm{M}$ rosiglitazone for the entire culture period, following the same protocol.

Preparation of conditioned media $(C M)$. To prepare the conditioned media of mature WAs and BAs, serum-free D-MEM/F-12 medium with $1 \%$ BSA was added to 12 -well plates containing WAs or BAs and cells were incubated for an additional $24 \mathrm{~h}$ at $37^{\circ} \mathrm{C}$ in $5 \% \mathrm{CO}_{2}$ (24). Subsequently, cells were removed by centrifugation, supernatants collected, aliquoted and immediately stored at $-80^{\circ} \mathrm{C}$. Control conditioned media (Ctrol-CM) were obtained by incubating empty 12-well culture plates with serum-free D-MEM/F-12 medium with $1 \% \mathrm{BSA}$ for $24 \mathrm{~h}$ at $37^{\circ} \mathrm{C}$ in $5 \% \mathrm{CO}_{2}$. Cell-free $\mathrm{CM}$ were used undiluted in the experiments.

Indirect immunofluorescence (IIF). Preadipocyte 3T3-L1 cells were grown on coverslips and differentiated into WAs or BAs following the protocol described above. On day 10, coverslips were washed with phosphate-buffered saline (PBS) and adipocytes were fixed in 4\% paraformaldehyde-sucrose (15 min), washed with PBS, permeabilized with $0.5 \%$ Triton X-100 in PBS (10 min) and blocked with high ionic strength buffer ( $20 \mathrm{mM}$ Tris- $\mathrm{HCl} \mathrm{pH} 8.0,0.63 \mathrm{M} \mathrm{NaCl}$, $1 \%$ BSA, $0.05 \%$ Tween-20 and $0.02 \%$ sodium azide) at room temperature (RT) for $1 \mathrm{~h}$. Cells were incubated overnight $(\mathrm{ON})$ at $4^{\circ} \mathrm{C}$ with polyclonal rabbit anti-UCP1 (dilution 1:500; cat. no. U6382; Sigma-Aldrich; Merck KGaA) or monoclonal mouse anti-GLUT4 (dilution 1:50; cat. no. sc-53566; Santa Cruz Biotechnology, Inc.), washed with PBS and blocked with $1 \%$ BSA in PBS ( $1 \mathrm{~h}$ at RT). Subsequently, coverslips were incubated with FITC (dilution 1:100; cat. no. F0382; Sigma-Aldrich; Merck KGaA) or Alexa Fluor 647 nm (dilution 1:100; Thermo Fisher Scientific, Inc.) conjugated secondary antibody for $1 \mathrm{~h}$ at RT. Nuclei were counterstained with Hoechst (cat. no. 33342; Thermo Fisher Scientific, Inc.) for $10 \mathrm{~min}$. For the staining of LDs, coverslips were inverted onto $25 \mu \mathrm{l}$ of Lipid-TOX (dilution 1:300; HCS Lipid-TOX ${ }^{\mathrm{TM}}$ Neutral lipid Stains, Invitrogen; Thermo Fisher Scientific, Inc.) following Hoechst staining, incubated $30 \mathrm{~min}$ at RT and mounted with Vectashield. Mitochondria were stained using MitoTracker ${ }^{\mathrm{TM}}$ Green FM (cat. no. M7514; Thermo Fisher Scientific, Inc.). Images were acquired with a Spinning Disk-TIRF-Olympus DSU-IX83 microscope (60x objective) and analyzed using ImageJ software (version 1.52p; NIH). A total of 200-300 cells were analyzed per condition and per experiment by two independent observers.

Gene expression by RT-qPCR analysis. Total RNA was extracted using Tri Reagent (cat. no. TR118; Molecular Research Center) according to the manufacturer's instructions. RNA quantity and quality were assessed spectrophotometrically (NanoDrop 2000; Thermo Fisher Scientific, Inc.). Following reverse transcription with EasyScript Reverse Transcriptase (TransGen Biotech), $1 \mu \mathrm{l}$ cDNA transcripts were amplified by real-time qPCR in a StepOne Real-Time PCR System in a $25 \mu \mathrm{l}$ reaction mixture containing $12.5 \mu \mathrm{l} \mathrm{SYBR}$ Green PCR Master Mix (both from Applied Biosystems; Thermo Fisher Scientific, Inc.) and the appropriate primer concentration. Primers used were: UCP1 forward, 5'-GTA CCAAGCTGTGCGATGTC-3' and reverse, 5'-ACATGATGA CGTTCCAGGAC-3'; CIDEA forward, 5'-TCAAACCAT GACCGAAGTAGC-3' and reverse, 5'-TCCAGCACCAGC GTAACC-3'; GLUT4 forward, 5'-TCAACCAGCATCTTC GAGTC-3' and reverse, 5'-AGATGGAGTGTCCGTCGTC-3'; $\beta$-actin forward, 5'-TGGCACCACACTTTCTACAAT-3' and reverse, 5'-GGTACGACCAGAGGCATACA-3'. The amplification program used was as follows: Initial denaturation step at $95^{\circ} \mathrm{C}$ for $10 \mathrm{~min}, 40$ denaturation cycles at $95^{\circ} \mathrm{C}$ for $15 \mathrm{sec}$ and annealing and extension steps at $60^{\circ} \mathrm{C}$ for $1 \mathrm{~min}$. The expression of selected genes was normalized to that of b-actin gene and the comparative $\Delta \Delta \mathrm{Cq}$ method $\left(2^{-\Delta \Delta \mathrm{Cq}}\right)$ (25) was used to calculate relative gene expression.

Western blotting $(W B)$. WB was performed to evaluate protein expression levels in cell lysates and conditioned media. Cells were lysed in lysis buffer (60 mM Tris-HCl, $1 \%$ SDS, pH 6.8). Sample protein content was determined by the Bradford method. Proteins (50-80 $\mu \mathrm{g}$ ) were resolved in an SDS-PAGE $12 \%$ gel, and electrotransferred to polyvinylidene fluoride membranes (PVDF) (Bio-Rad Laboratories, Inc.). After blocking in $1 \%$ BSA for $1 \mathrm{~h}$, the membranes were incubated with the different primary antibodies $\mathrm{ON}$ at $4^{\circ} \mathrm{C}$ as follows. Polyclonal rabbit anti-UCP1 (dilution 1:1,000; cat. no. U6382; Sigma-Aldrich; Merck KGaA), polyclonal rabbit anti-leptin (dilution 1:1,000; cat. no. ab117751; Abcam), polyclonal rabbit anti-caveolin 1 (dilution 1:2,000; cat. no. 610060; BD Transduction Laboratories), polyclonal goat anti-vimentin (dilution 1:50; cat. no. V4630; Sigma-Aldrich; Merck $\mathrm{KGaA}$ ), polyclonal rabbit anti-perilipin 1 (dilution 1:2,000; cat. no. ab3526; Abcam), polyclonal rabbit anti-HSL (dilution 1:1,000; cat. no. ab45422; Abcam), monoclonal rabbit anti-FABP4 (dilution 1:1,000; cat. no. ab219595; Abcam) and monoclonal mouse anti-adiponectin (dilution 1:1,000; cat. no. sc-136131; Santa Cruz Biotechnology, Inc.) antibodies were used to measure protein expression in mature WAs and BAs on day 10 and in WA-CM and BA-CM. Polyclonal rabbit anti-MCT4 (dilution 1:500; cat. no. sc-50329 H90; Santa Cruz Biotechnology, Inc.) antibody was used to measure protein expression in adipocyte lysates. Vimentin, polyclonal rabbit anti-CD44 (dilution 1:2,000; cat. no. ab157107; Abcam), polyclonal rabbit anti-ObR (dilution 1:500; cat. no. sc-8325; Santa Cruz Biotechnology, Inc.), polyclonal mouse anti-MCT1 (dilution 1:500; cat. no. ab90582; Abcam), polyclonal goat anti-MMP-9 (1:500; cat. no. AF909; R\&D Systems) and polyclonal rabbit anti-LDH (dilution 1:1,000; cat. no. ab47010; Abcam) antibodies were used to measure protein expression after treatment of non-tumor or tumor epithelial cells with CM. Following incubation in the primary antibody, membranes were washed and incubated with the corresponding HRP-conjugated secondary antibody: anti-rabbit (dilution 1:6,000; cat. no. A0545; Sigma-Aldrich; Merck KGaA), anti-goat (dilution 1:7,500; cat. no. A5420; Sigma-Aldrich; Merck KGaA) or anti-mouse (dilution 1:4,000; cat. no. sc-2005; Santa Cruz Biotechnology, Inc.). Antibody complexes were visualized by chemiluminescence [ECL solution containing luminol (cat. no. 123072; Sigma-Aldrich; Merck KGaA), $p$-coumaric acid (cat. no. C9008; Sigma-Aldrich; Merck KGaA) and $\mathrm{H}_{2} \mathrm{O}_{2}$ ]. Bands were quantified by densitometry using ImageJ 
software. Actin (dilution 1:1,000; cat. no. sc-1616; Santa Cruz Biotechnology, Inc.) levels were used as loading control.

Oil Red $O$ staining and analysis of triglyceride content. Oil Red O staining and quantification of TG content were performed as previously described (26) using a $0.2 \%$ Oil Red O solution in 40\% 2-propanol. After staining, cell images were captured in an inverted phase-contrast microscope (Olympus CKX-41; objective 20x) and the average number of LDs per cell recorded in WAs and BAs using ImageJ software. TG content was quantified by incubating culture plates in 100\% 2-propanol for $10 \mathrm{~min}$ at RT on an orbital shaker to elute the Oil Red O dye. The eluted dye was transferred to a 96-well plate and the absorbance was measured at $510 \mathrm{~nm}$ using a multimodal microplate reader (Synergy HTX S1LFA S/N 18062619; BioTek Instruments). Assay was performed in quadruplicate.

Measurement of lactate in conditioned media. To quantify extracellular lactate released by mature WAs and BAs on day 10, CM were obtained from adipocytes incubated with D-MEM/F-12, 1\% BSA for $24 \mathrm{~h}$. Supernatants were recovered, and cell debris was removed by centrifugation. Lactate was measured by a standard method involving the conversion of $\mathrm{NAD}^{+}$to NADH and subsequent spectrophotometric determination of NADH at $340 \mathrm{~nm}$. A commercial kit (Sigma-Aldrich; Merck KGaA) was used to carry out the determination as indicated by the manufacturer. Results are expressed as $\mu \mathrm{g}$ of lactate/100 $\mu \mathrm{l}$.

Cell adhesion assay. The adhesion capacity of cell lines was analyzed following treatment with WA-CM or BA-CM. For this purpose, $1 \times 10^{5}$ cells/well of non-tumor mammary epithelial cell lines (NMuMG) or tumor cells (LM3, 4T1 and MC4-L1) were seeded in 12-well plates in D-MEM/F-12 supplemented with $10 \%$ FBS. Twenty-four hours later, the cells were washed with PBS and incubated for another $24 \mathrm{~h}$ with WA-CM, BA-CM or Ctrol-CM. Cells were then harvested and re-seeded in duplicate or triplicate in a 96 -well plate $\left(5 \times 10^{4}\right.$ cells/well). After $1 \mathrm{~h}$, medium containing the unattached cells was aspirated, adhered cells washed with PBS and, $3 \mathrm{~h}$ later, adhesion was assessed by the MTS assay measuring absorbance at $490 \mathrm{~nm}$ in a multimodal microplate reader (Synergy HTX S1LFA S/N 18062619; BioTek Instruments).

\section{Cell migration assays.}

Wound healing assay. The effect of WA-CM or BA-CM on the motility of tumor and non-tumor mammary epithelial cell lines was evaluated by wound healing assays. NMuMG, LM3, 4T1 and MC4-L1 cells were grown on 96-well plates with supplemented D-MEM/F-12 until cells reached $100 \%$ confluence. Afterwards, cell monolayers were scratched with a 200- $\mu$ l pipette tip, washed twice with PBS and WA-CM, BA-CM or Ctrol-CM were added to the wells. CM were obtained as previously described in a serum-free D-MEM/F-12 medium with $1 \%$ BSA and used undiluted. Images at time zero $(0 \mathrm{~h})$ were obtained to record the initial width of the wounds, and the recovery of the wounded area was evaluated at 6 and $12 \mathrm{~h}$. Images of the wound closure were captured using an inverted microscope (Olympus CKX-41; objective 4x), quantitative analysis of wounds was performed by ImageJ software and the relative wound closure was calculated with respect to $0 \mathrm{~h}$.

Transwell migration assay. The effect of WAs or BAs on the motility of tumor and non-tumor mammary epithelial cells was analyzed by Transwell migration assay. NMuMG, LM3, 4T1 and MC4-L1 mammary cell lines $\left(1.5 \times 10^{4}\right.$ cells/well $)$ were placed into Transwells [8- $\mu \mathrm{m}$ pore membrane (top); Jet BIOFIL cat. no. TCS-013-024] containing serum-free D-MEM/F-12 $1 \%$ BSA medium. The inserts were immediately transferred to 24-well plates with mature WAs or BAs at the bottom of the well. Given that LM3 and 4T1 epithelial cells have a high basal migration rate whereas NMuMG and MC4-L1 cell lines present a very low basal migration rate, Transwell migration assays were performed for 6,12 and $24 \mathrm{~h}$ in all mouse mammary cells studied. After tumor and non-tumor mammary epithelial cells were allowed to migrate across the membrane, the inserts were removed, washed with PBS, and the mammary cells were fixed with cold methanol for $30 \mathrm{~min}$, washed with PBS and stained with Hoechst (cat. no. 33342; Thermo Fisher Scientific, Inc.) $1 \mu \mathrm{g} / \mathrm{ml}$ for $10 \mathrm{~min}$ and non-migrating cells were removed with a wet cotton. Air-dried membranes were imaged at $\times 40$ magnification under an inverted microscope (Olympus CK-41) and migrated cells were counted in 10 randomly chosen fields per membrane with ImageJ software.

Statistical analysis. Experiments were repeated at least twice with similar results. Data are presented as mean \pm SEM. Student's t-test, the Mann-Whitney test or one-way analysis of variance (ANOVA) followed by Tukey's multiple comparison test was performed as needed. Differences were considered significant at $\mathrm{P}<0.05$.

\section{Results}

Characteristics of the WAs and BAs differentiated from 3T3-L1 preadipocytes. Indirect immunofluorescence was performed in 3T3-L1 adipose cells to assess the expression and localization of beige markers. As expected, the presence of $1 \mu \mathrm{M}$ rosiglitazone (Rosi), a specific agonist of peroxisome proliferator-activated receptor $\gamma$ (PPAR $\gamma$ ), in the differentiation cocktail significantly increased the expression of UCP1 (Fig. 1A, bottom panels). UCP1 showed a punctate staining pattern like the one observed with Mitotracker (Fig. 1A vs. B, bottom panels). Interestingly, BAs displayed round-shaped mitochondria, suggesting sustained fission activity (Fig. 1B, white arrow head in bottom panels), while WAs showed a mix of tubular (white arrow in top panels, Fig. 1B) and partially fragmented mitochondria (white arrow head in top panels Fig. 1B). Fragmented mitochondria with round-shaped morphology were not found in undifferentiated 3T3-L1 preadipocytes treated with rosiglitazone (Fig. 1B, bottom panels, a fibroblast adjacent to an adipocyte occupies the bottom right in first panel and can be seen at higher magnification in third panel), excluding an effect of PPAR $\gamma$ activation on fission events.

There is evidence that brown/beige adipocytes express high levels of GLUT4, and consume glucose at significantly higher levels $(20,27)$. An increase in GLUT4 fluorescence intensity was observed in BAs in comparison to WAs (Fig. 1C, bottom vs. top panels), and BAs showed an increase in the 

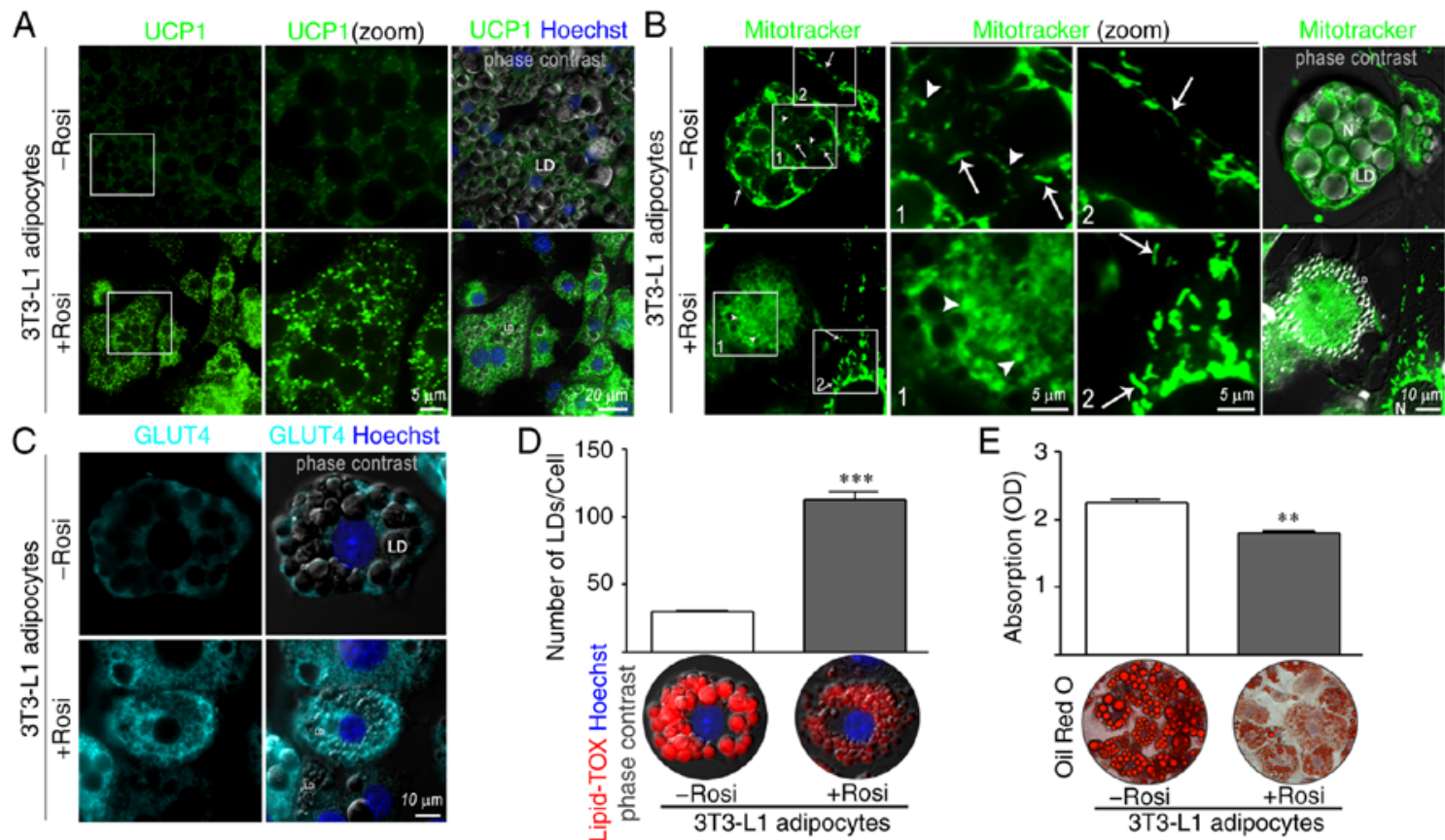

Figure 1. Characteristics of WAs and BAs differentiated from 3T3-L1 preadipocytes. (A and C) Expression and localization of UCP1 and GLUT4, and localization of lipid droplets (LDs) were evaluated by IIF. 3T3-L1 preadipocytes were grown on coverslips and induced to differentiate into WAs (3T3-L1 adipocytes-Rosi) or BAs (3T3-L1 adipocytes +Rosi) using $1 \mu \mathrm{M}$ rosiglitazone (Rosi). On day 10, adipocytes were fixed and incubated with the indicated antibodies. Nuclei were counterstained with Hoechst. Images were analyzed by confocal microscopy (magnification, x600). (B) WAs or BAs were incubated with $200 \mathrm{nM}$ MitoTracker Green for $15 \mathrm{~min}$ followed by wash-out before imaging. White arrow heads show examples of round-shaped mitochondria and white arrows show examples of tubular mitochondria. Boxed areas are shown as zoomed images on right (zoom). LD, lipid droplet; N, nuclei. (D) LDs in WAs or BAs were stained with Lipid-TOX. The average number of LD per cell was quantified in WAs and BAs using ImageJ software (version 1.52p; NIH). Representative confocal microscopy images are shown. (E) 3T3-L1 cells differentiated into WAs or BAs, were stained with Oil Red O and images were acquired in a phase contrast microscope. Representative light microscopy images (magnification, x200) are shown. TG content in WAs and BAs was quantified by measuring the absorbance of extracted lipid stain at $510 \mathrm{~nm}$. ( $\mathrm{n}=4-5$ experiments in triplicate). Mann-Whitney test was performed; ${ }^{* * *} \mathrm{P}<0.01$ and ${ }^{* * * *} \mathrm{P}<0.001$, compared with the -Rosi group. Rosi, rosiglitazone; WAs, white adipocytes; BAs, beige adipocytes; TG, triglyceride; UCP1, uncoupled protein 1; GLUT4, glucose transporter 4; IIF, indirect immunofluorescence.

number of micro-LDs (Fig. 1D, +Rosi) but a decrease in TG accumulation compared to WAs (Fig. 1E +Rosi vs. -Rosi).

Expression levels of beige markers and GLUT4, leptin and MCT4 were measured in WAs and BAs differentiated from 3T3-L1 preadipocytes. The increased fluorescence intensity of UCP1 and GLUT4 previously observed in BAs was confirmed by RT-qPCR (Fig. 2A). The expression of Ucpl, Cidea (another classic beige/brown marker), and Glut 4 was significantly higher in 3T3-L1 adipose cells after PPAR $\gamma$ activation. Expression levels of UCP1, HSL, perilipin 1, adiponectin, leptin, FABP4, caveolin 1, vimentin and the metabolic markers MCT4 and LDH were evaluated in WAs and BAs (Fig. 2B). Perilipin 1, the main protein coat for LDs in mature adipocytes, and HSL are two proteins involved in the lipolytic process.

Perilipin 1 expression was slightly decreased in the BAs compared to the WAs; HSL levels were not affected by rosiglitazone treatment. Adiponectin and leptin are the main adipokines released by adipocytes; worthy of note, there was a higher leptin expression but significantly lower adiponectin expression in BAs when compared to the WAs (Fig. 2B). Caveolin-1 is an important protein, necessary for LD formation (28), and a marked decrease in caveolin 1 expression was observed in the BAs (Fig. 2B), in agreement with a decrease in lipid accumulation (Fig. 1E). The expression of FABP4, actively secreted and essential to modulate lipid fluxes, trafficking, signaling and metabolism in adipocytes, was increased in BAs, while a decrease in vimentin expression was observed in BAs when compared to WAs (Fig. 2B). The expression of MCT4, a mediator of lactate export, was increased in BAs relative to WAs (Fig. 2B); expression levels of LDH, enzyme catalyzing the conversion of pyruvate to lactate, were similar to those of MCT4 (data not shown).

Expression of leptin, FABP4, UCP1, adiponectin, caveolin 1 and vimentin and lactate efflux in WA-CM and BA-CM. To characterize soluble factors present in WA-CM and BA-CM, the expression levels of different proteins were determined by WB. According to Fig. 3A and B, the results showed significantly increased expression of leptin in BA-CM compared to WA-CM, while adiponectin and caveolin 1 expression was significantly decreased. Vimentin was present in both WAand $\mathrm{BA}-\mathrm{CM}$, but the expression levels were not significantly different. Increased expression of FABP4 and UCP1 was found in BA-CM in comparison to WA-CM. Worthy of note, changes in expression levels of leptin, adiponectin, caveolin 1, UCP1 and FABP4 in CM (Fig. 3A and B) agree with those observed in the cellular extracts (Fig. 2B). Expression levels of HSL (Fig. 3A) and perilipin 1 (data not shown) were insignificant in both $\mathrm{CM}$.

We investigated whether the upregulation of MCT4 and LDH upon differentiation into BAs translated into an 

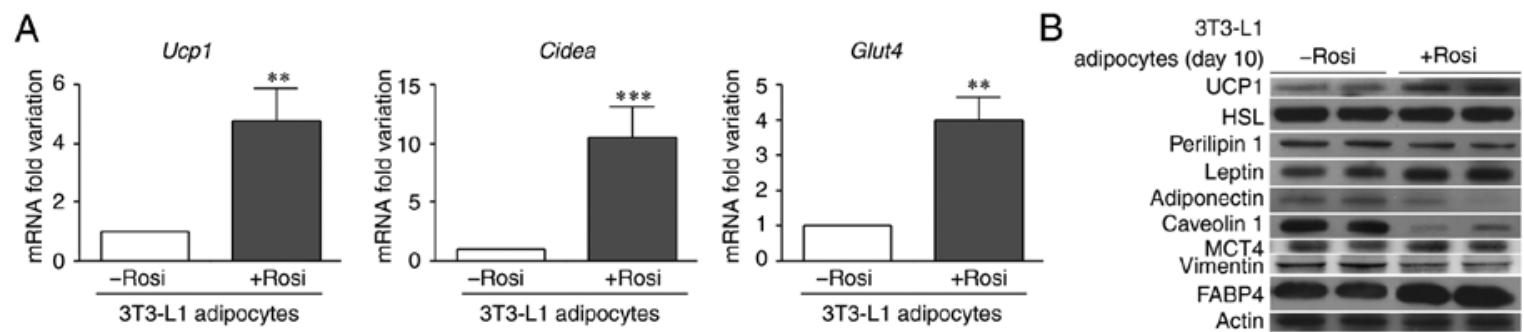

Figure 2. Expression levels of different brown/beige/white adipocyte markers. (A) 3T3-L1 preadipocytes were differentiated into WAs or BAs (3T3-L1 adipocytes -Rosi or +Rosi, respectively). On day 10, mRNA was extracted for the RT-qPCR analysis of Ucpl, Cidea and Glut4, and (B) protein was extracted for immunoblot analysis of the expression of UCP1, HSL, perilipin 1, leptin, adiponectin, caveolin 1, MCT4, vimentin, and FABP4. Actin was used as a loading control. ( $\mathrm{n}=3-4$ experiments in triplicate). Mann-Whitney test was performed; ${ }^{* *} \mathrm{P}<0.01$ and ${ }^{* * *} \mathrm{P}<0.001$, compared with the - Rosi group. WAs, white adipocytes; BAs, beige adipocytes; UCP1, uncoupled protein 1; Cidea, cell death-inducing DFFA-like effector A; GLUT4, glucose transporter 4; FABP4, fatty acid binding protein 4; MCT4, monocarboxylate transporter 4; HSL, hormone-sensitive lipase.
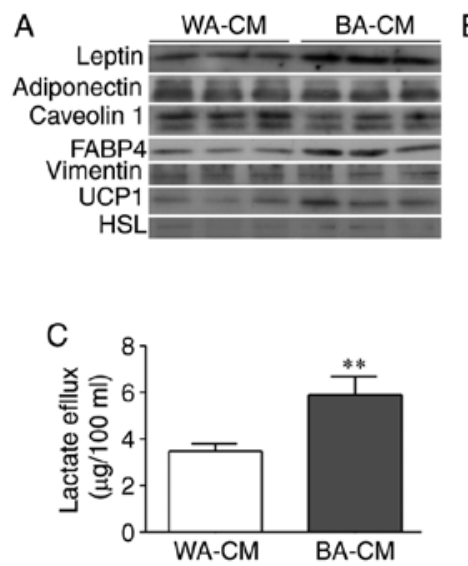
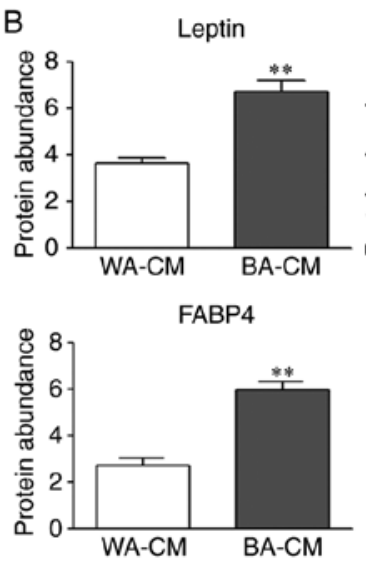
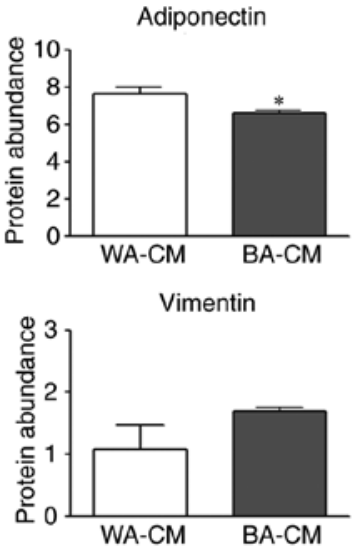

Caveolin 1
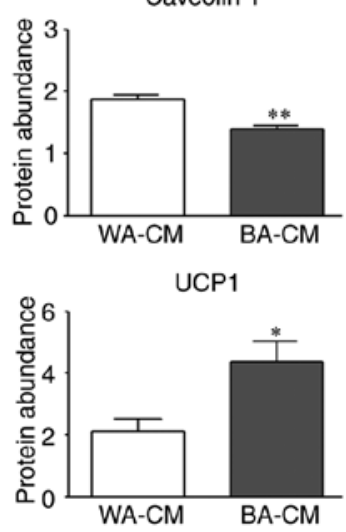

Figure 3. Expression levels of a different set of proteins in WA-CM and BA-CM. (A and B) Leptin, adiponectin, caveolin 1, FABP4, vimentin, UCP1 and HSL expression was analyzed by WB and images were analyzed by densitometry. (C) The levels of lactate secreted by WAs or BAs were determined by colorimetric assay (WA-CM and BA-CM collected after $24 \mathrm{~h}$ of incubation) ( $\mathrm{n}=3$ experiments in triplicate). Mann-Whitney test was performed; ${ }^{*} \mathrm{P}<0.05$ and ${ }^{* *} \mathrm{P}<0.01$, compared with WA-CM. WB, western blotting; WA, white adipocyte; BA, beige adipocyte; CM, conditioned media; UCP1, uncoupled protein 1; FABP4, fatty acid binding protein 4; HSL, hormone-sensitive lipase.
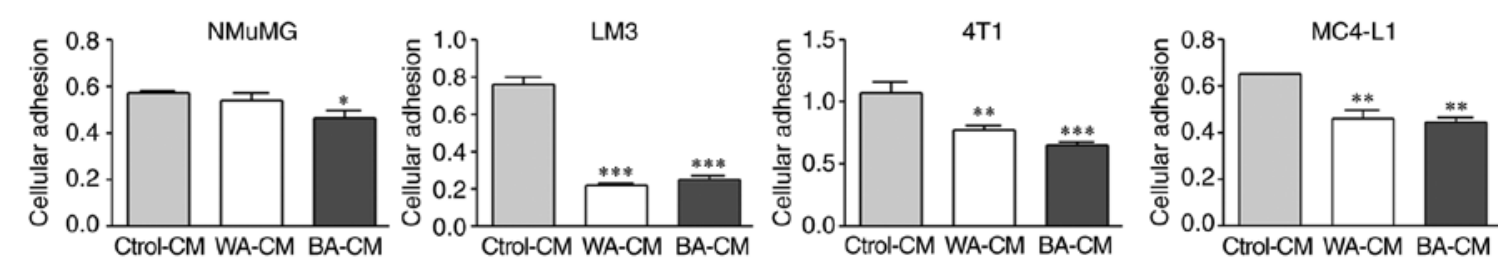

Figure 4. Effect of CM from WAs and BAs on the attachment of NMuMG, LM3, 4T1 and MC4-L1 cells. Non-tumor (NMuMG) and tumor (LM3, 4T1 and MC4-L1) epithelial cells were treated with WA-CM, BA-CM or Ctrol-CM for $24 \mathrm{~h}$. After treatment, the cells were plated at a density of 5x10 4 cells/well in 96-well plates and adherent cells were quantified by MTS after $1 \mathrm{~h}$ ( $\mathrm{n}=2$ experiments in triplicate). Tukey's multiple comparison test was performed; * $\mathrm{P}<0.05$, ${ }^{* *} \mathrm{P}<0.01$ and $^{* * *} \mathrm{P}<0.001$, compared with the Ctrol-CM group. WA, white adipocyte; BA, beige adipocyte; CM, conditioned media.

increased lactate flux. Lactate efflux from WAs and BAs, evaluated in WA- and BA-CM using a colorimetric assay, showed that lactate transporter capacity was increased in 3T3-L1 differentiated into a beige phenotype (Fig. 3C).

Effect of BA-CM on cellular adhesion of mammary epithelial cells. To compare the presence of soluble factors in WA-CM and BA-CM, that could affect tumor cell adhesion, NMuMG, LM3, 4T1 and MC4-L1 epithelial cells were exposed to different CM (WA-, BA- or Ctrol-CM) and cell adhesion was determined as described in Materials and methods. WA-CM and BA-CM significantly decreased adhesion of LM3, 4T1 and
MC4-L1 cells with respect to Ctrol-CM (Fig. 4). On the other hand, NMuMG cell adhesion was decreased significantly after incubation with BA-CM vs. both WA-CM and Ctrol-CM.

Effect of BA-CM on tumor and non-tumor mammary epithelial cell migration. To evaluate the effect of WA-CM and BA-CM on the migratory capacity of tumor and non-tumor mammary epithelial cells, we performed wound healing assays. WA-CM and BA-CM significantly increased migration of LM3 and 4T1 (tumor) cells after incubating for $6 \mathrm{~h}$, and of MC4-L1 (tumor) and NMuMG (non-tumor) after incubating for $12 \mathrm{~h}$ vs. the Ctrol-CM (Fig. 5). These results suggest that BA-CM 

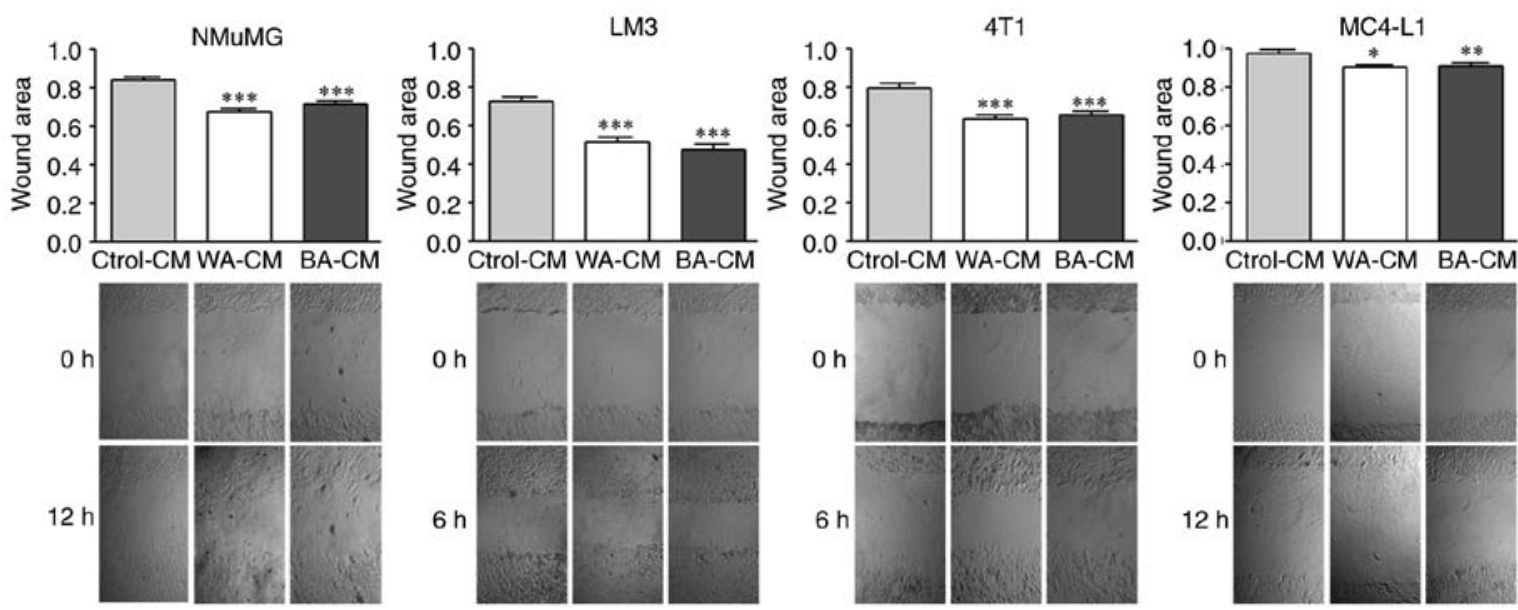

Figure 5. Effect of CM from WAs and BAs on the migration of NMuMG, LM3, 4T1 and MC4-L1 cells. Non-tumor (NMuMG) and tumor (LM3, 4T1 and MC4-L1) epithelial cells were grown to confluence on 96-well plates in the presence of complete D-MEM/F-12 medium. Wounds were formed, and WA-CM, BA-CM or Ctrol-CM were added. Images of the wound closure were acquired immediately after the wound was made $(0 \mathrm{~h})$, and after 6 and $12 \mathrm{~h}$. Representative zoomed areas from light microscopy images (magnification, $\mathrm{x} 40$ ) are shown. Graph shows the ratio of 12/0 h (NMuMG and MC4-L1) or 6/0 h (LM3 and 4T1) wounded areas ( $\mathrm{n}=3$ experiments in duplicate). Tukey's multiple comparison test was performed; ${ }^{*} \mathrm{P}<0.05,{ }^{* * *} \mathrm{P}<0.01$ and ${ }^{* * * *} \mathrm{P}<0.001$, compared with the Ctrol-CM group. WA, white adipocyte; BA, beige adipocyte; CM, conditioned media.
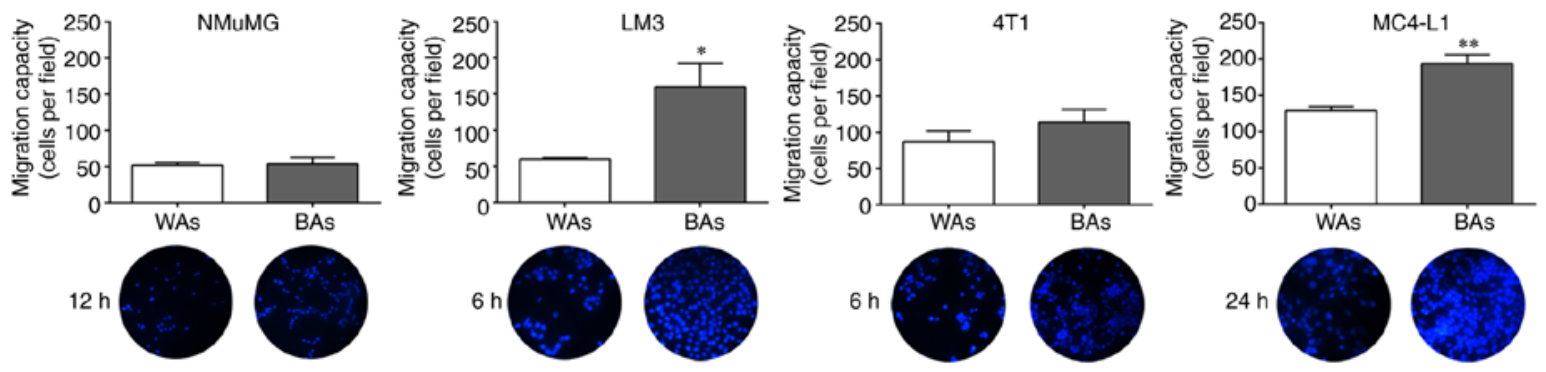

Figure 6. Chemotactic capacity of WAs and BAs on migration of non-tumor and tumor epithelial cells. Non-tumor (NMuMG) and tumor (LM3, 4T1 and MC4-L1) epithelial cells were added in the top chamber onto the porous membrane, and were allowed to migrate across the membrane towards WAs or BAs present in the bottom chamber, for 6,12 or $24 \mathrm{~h}$. The membranes were viewed under a light microscope (magnification, x40). Migrated cells were counted in 10 randomly chosen fields per membrane ( $\mathrm{n}=2$ experiments in triplicate). Student's $\mathrm{t}$-test was performed; ${ }^{*} \mathrm{P}<0.05,{ }^{* *} \mathrm{P}<0.01$, compared with the WA group. WAs, white adipocytes; BAs, beige adipocytes.

increase the migration capacity of both tumor and non-tumor mammary epithelial cells in agreement with results found in the cell adhesion assays (Fig. 4).

Transwell migration of tumor cells in the presence of BAs. To compare the chemotactic capacity of BAs and WAs on tumor and non-tumor epithelial cell migration, Transwell migration assays were performed as described in Materials and methods. BAs significantly increased cell migration of LM3 and MC4-L1 cells vs. the WAs, following incubation for 6 and 24 h, respectively (Fig. 6). BAs also increased 4T1 cell migration after incubation for $6 \mathrm{~h}$ though to a lesser extent, but there was no significant chemotactic effect of BAs or WAs on NMuMG migration at any time tested.

Taken together, these results suggest that crosstalk takes place between tumor cells and BAs and that this cell-cell communication may be necessary to modulate adipocyte action on epithelial cell migration, beyond the effect of soluble factors.

Effect of soluble factors from WAs and BAs on ObR, CD44, vimentin, MMP-9, MCT1 and LDH expression level in
NMuMG, 4T1, LM3 and MC4-L1 cell lines. The effect of soluble factors released by WAs and BAs on the expression level of several tumor progression markers, was evaluated by WB in tumor and non-tumor epithelial cells incubated with WA-CM, BA-CM or Ctrol-CM for $24 \mathrm{~h}$. ObR and MMP-9 expression in MC4-L1 cells was significantly higher when incubated with BA-CM compared to WA-CM or Ctrol-CM (Fig. 7, MC4-L1). CD44 expression showed an increasing trend in MC4-L1 cells incubated with BA-CM (Fig. 7, MC4-L1), but differences were not significant. By contrast, MMP-9 expression was significantly lower when NMuMG (non-tumor) cells were treated with BA-CM and WA-CM vs. Ctrol-CM and, interestingly, CD44 and ObR expression levels were significantly decreased in LM3 and 4T1, respectively, after treatment with WA-CM. Vimentin expression level was not affected by different CM treatments and, surprisingly, neither were MCT1 and LDH expression levels (Fig. 7).

\section{Discussion}

Bidirectional communication between epithelial cells and cells from the stromal compartment is essential for tumor 

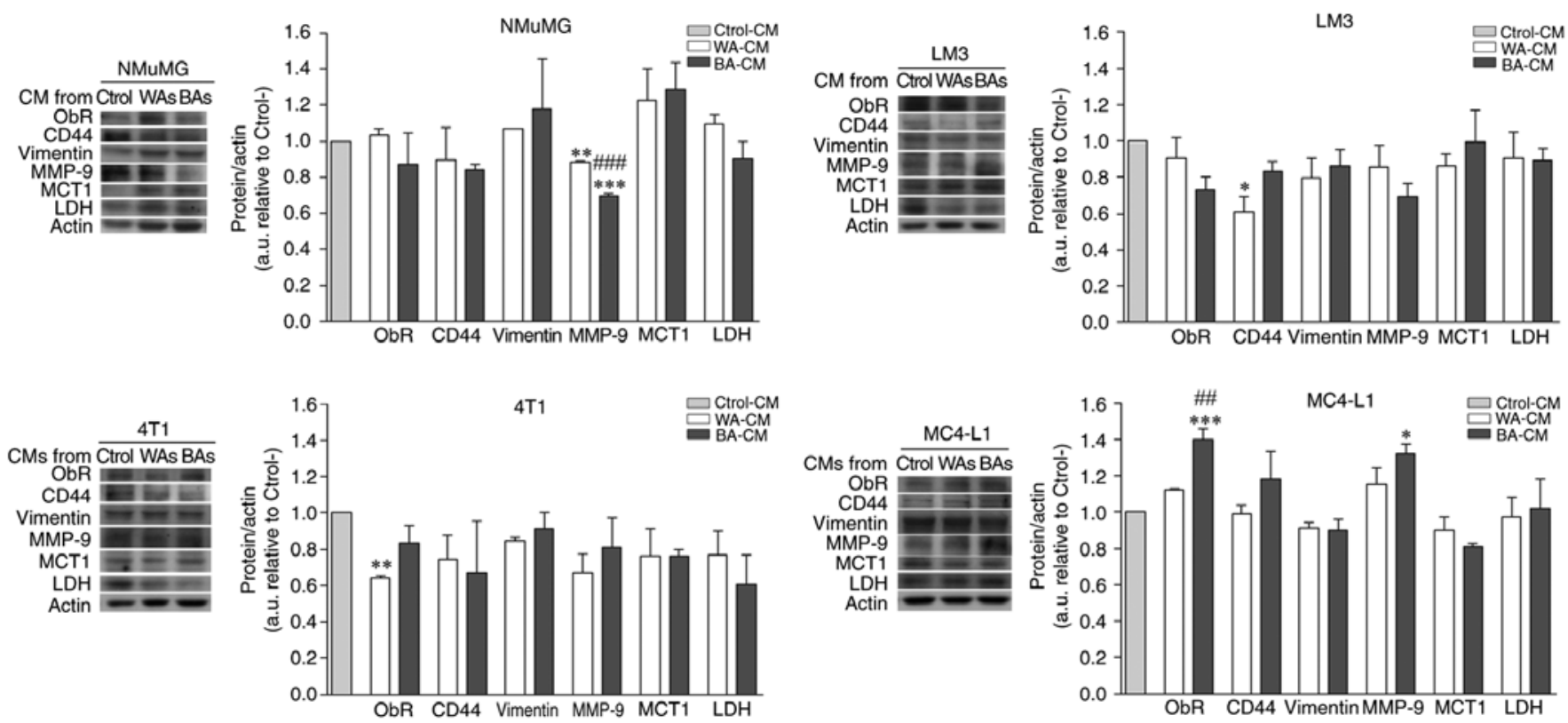

Figure 7. Effect of CM from WAs and BAs on the expression levels of several tumor progression and metabolic markers was evaluated in mammary epithelial cells. Non-tumor and tumor cells were grown on 6-well plates, incubated for $24 \mathrm{~h}$ with the different CM and, then, lysed. The expression of ObR, CD44, vimentin, MMP-9, MCT1 and LDH was analyzed by WB. Actin was used as a loading control. Images were analyzed by densitometry (n=2 experiments in triplicate). Tukey's multiple comparison test was performed; ${ }^{*} \mathrm{P}<0.05,{ }^{* *} \mathrm{P}<0.01$ and ${ }^{* * *} \mathrm{P}<0.001$, cells incubated with WA-CM or BA-CM vs. Ctrol-CM; ${ }^{\# \#} \mathrm{P}<0.01$ and ${ }^{\# \#} \mathrm{P}<0.001$, cells incubated with BA-CM vs. WA-CM. WA, white adipocyte; BA, beige adipocyte; CM, conditioned media; MCT1, monocarboxylate transporter 1; ObR, leptin receptor; MMP-9, matrix metalloprotease 9; LDH, lactate dehydrogenase.

development and maintenance of a cancerous phenotype, whether invasive or not $(2,29)$. This crosstalk can either trigger cancerous behavior and support it or, eventually, lead to involution to a non-tumor form. Invading cancer cells can dramatically impact the surrounding adipose cells that exhibit an altered phenotype and specific biological features (e.g. lipid loss and overexpression of inflammatory cytokines) suggesting that adipose cells in the tumor environment present a less differentiated state than adipocytes in a normal microenvironment (3,30-32). Multiple lines of evidence obtained in vitro and in vivo have demonstrated that an increased expression of beige/brown adipose tissue key markers occurs during breast tumor development $(16,18,21)$ and this, is in turn, promotes tumor progression $(19,33)$. In the present study, we evaluated the possible role of beige adipocytes (BAs) in the control of mammary epithelial cell pathophysiology.

We characterized the cell phenotype of mouse BAs obtained in vitro after treatment of 3T3-L1 preadipocytes with rosiglitazone, a known peroxisome proliferator-activated receptor $\gamma(\operatorname{PPAR} \gamma)$ activator which has been described as acting in vivo in mouse white fat depots (34). Our results showed that upon PPAR $\gamma$ activation, 3T3-L1 adipocytes displayed multilocular micro-lipid droplet (LD) morphology and expressed brown fat-specific genes such as Ucpl and Cidea. The shift in adipocyte phenotype (white to beige) involves marked changes in the metabolic state of mitochondria (35). Accordingly, our results showed UCP1-positive mitochondria preferentially displaying a round shape (mitochondrial fission), whereas UCP1-negative mitochondria appeared tubular and elongated, in agreement with previous findings in mice and human brown/beige adipocytes (36-38). Thus, mitochondrial fission in 3T3-L1 BAs may be considered a physiological adaptation rather than a purely deleterious mechanism (36).

The pathways mainly regulated by rosiglitazone in 3T3-L1 adipocytes are fatty acid oxidation, the TCA cycle and oxidative phosphorylation. Rosiglitazone induces adipocytes to utilize fatty acids for energy production, increasing lipolysis and reducing lipogenesis, and spare glucose and amino acids by enhancing glycogen synthesis and inhibiting amino acid catabolic pathways. This is in line with the upregulation of UCP1 and downregulation of perilipin 1 observed in this study, which thus act as gatekeepers of lipolysis regulation. Increased levels of UCP1 correlate with a shift in substrate utilization, favoring lipids as the dominant metabolic fuel $(10,39)$.

Metabolic reprogramming is an emerging hallmark of cancer $(40,41)$. There is evidence that suggests that the expression of monocarboxylate transporters (MCTs), mediators of lactate flux, is modified when metabolic demands of the tissue are being altered (42), and that MCT upregulation is important for the normal physiological function of mature adipose cells (43). Our results showed that both MCT4 expression and lactate flux capacity were increased in BAs. MCT1 and MCT4 have now been confirmed as prominent facilitators of lactate exchange between cancer and stromal cells $(44,45)$. In fact, it is likely that an elevated expression of MCT4 in stromal adipose tissue concomitantly with MCT1 overexpression in malignant tissue, may be an important clinical biomarker for poor prognosis in breast cancer patients $(19,45)$.

Cancer cells take up free fatty acids and glycerol, besides glucose, as a source of energy from adjacent adipocytes. Thus, BAs could pose as an important energy storage providing tumor cells with high energy metabolites such as lactate, a situation known as the reverse Warburg effect $(46,47)$. Our 
results showed no significant differences in the expression levels of MCT1, a key transporter for the uptake of lactate into cells, when tumor or non-tumor epithelial cells were incubated with beige adipocyte-conditioned media (BA-CM). However, the possibility that lack of response in our study was due to the experimental setup cannot be ruled out. Additional studies examining the effect of white adipocyte (WA)-CM and BA-CM and adipocyte-epithelial cell co-culture on intracellular signaling pathways of non-tumor and tumor epithelial cells are currently in progress.

Adipokines, secreted in large amounts by adipose tissue, can act in an autocrine, paracrine, and/or endocrine manner to control various cellular processes, including those involved in the aggressive biological behavior of breast cancers (48). Adiponectin and leptin are the two main adipokines secreted by adipocytes. Plasma leptin levels are increased in breast cancer patients, correlating with higher grade, advanced tumor stage and aggressive subtypes (49) and leptin expression is increased in breast cancer peritumoral stroma (50). Leptin, by binding to the leptin receptor (ObR), promotes proliferation and development of breast cancer cells (49). Serum adiponectin levels seem to be significantly decreased in breast cancer patients, while antiproliferative effects of adiponectin, cell cycle inhibition and apoptosis activation have been verified (49). We previously reported a decrease in adiponectin expression in peritumoral adipose tissue compared to adipose tissue distant from the tumor (3). The present results revealed that leptin synthesis and secretion were increased in BAs, while adiponectin was decreased, further supporting the contention that the presence of BAs within breast cancer peritumoral adipose tissue could contribute to adipokine imbalance observed in the tumor microenvironment.

Fatty acid binding protein 4 (FABP4), a fatty acid transport protein, is another important adipokine that can regulate systemic metabolism $(51,52)$ and could be involved in cancer cell growth and metastasis $(29,52)$. Guaita-Esteruelas et al proposed that exogenous FABP4, which is responsive to signals that induce lipolysis, facilitates the uptake of fatty acids into breast cancer cells, playing a key role in tumor progression $(53,54)$. On the other hand, Witkiewicz et al showed that a reduction or loss of stromal caveolin 1 expression is usually associated with increased risk of early tumor recurrence, metastasis and decreased overall survival (55). Our results showed increased FABP4 expression and decreased caveolin 1 in BAs which, taken together with an increased mobility of fatty acids induced by UCP1 activation (56), suggest that BA tissue could promote tumor cell progression. Worthy of note, upregulation of UCP1 is considered a hallmark of metabolic stress associated with poor survival in breast cancer $(19,57,58)$.

The ability of WA-CM to modify breast tumor progression has been reported in several studies $(19,24)$. Interestingly, in this study, incubation of LM3, 4T1 and MC4-L1 (tumor) cells with both BA-CM or WA-CM produced a significant decrease in cell adhesion and increase in cell migration vs. Ctrol-CM. However, when chemotactic capacity of BAs and WAs on tumor and non-tumor epithelial cell migration was evaluated, BAs significantly increased cell migration in LM3 and MC4-L1 cell lines vs. WAs, suggesting that the presence of BAs modified the microenvironment promoting migration of epithelial cells. Adipose cells are known to affect tumor properties through various signaling processes, a crosstalk that can only happen when both cell types are in close contact during tumor progression and metastasis formation $(2,59)$. Supporting our results, Wu et al proposed that the preliminary step in this close interaction could be the capacity of tumor cells to induce this beige/brown differentiation and lipolysis in adipose cells (19). The effect of BA-CM on cell adhesion of NMuMG (non-tumor) cells was significantly higher than WA-CM, suggesting that soluble factors of WA-CM and BA-CM had a differential effect on non-tumor epithelial cells.

Despite the fact that there were no significant differences between BA-CM and WA-CM effects on cell adhesion and migration in tumor cells, MC4-L1 cells showed higher ObR and MMP-9 expression levels after incubation with BA-CM compared to WA-CM or Ctrol-CM. The invasion of tumor cells into healthy tissues is promoted by a necessary local proteolysis of the extracellular matrix (ECM), which involves the activity of metalloproteases (MMPs) (60). MMP-2 and MMP-9 play a fundamental role in proteolytic matrix degradation during invasion and metastasis, and an increase in MMP-2 and MMP-9 in human breast tumors has been associated with poor patient prognosis (60). Increased expression of MMP-9 in MC4-L1 cells could thus favor degradation of the basement membrane, an essential early step in tumor invasion. In agreement with this result, BA-CM also increased the expression of CD44 in the MC4-L1 cell line, a membrane glycoprotein involved in tumor cell migration and invasion processes $(61,62)$. We have recently shown that incubation of MCF7 and IBH-7 cells with CM from human breast cancer adipose tissue explants, stimulates the expression of CD44 (3). Taken together, our results indicate that one or more soluble factors present in CM from BAs could increase the subpopulation of MC4-L1 cells with high levels of CD44 and MMP-9, promoting cellular migration and consequently inducing cancer cell invasion. This evidence is clinically significant given that MC4-L1 cells are a luminal breast cancer model and luminal type accounts for more than $30-45 \%$ of breast cancers. Further studies are necessary to determine whether there is crosstalk signaling between BAs and molecular subtypes of breast cancer cells. Knockdown of CD44 and ObR genes in LM3 and MC4-L1 epithelial cells would lead us to achieve a more detailed comprehension of BA function in breast cancer progression. We are trying to solve this experimental limitation in a current study, trying to understand whether BAs are key actors in breast cancer development and maintenance of a cancerous phenotype.

Taken together, the results obtained in this study encourage us to speculate that breast cancer cells could increase $\mathrm{BA}$ recruitment or induce beige/brown differentiation in surrounding white fat, as a strategy to reduce energy storage in adipocytes which would then be acting as a metabolic fuel source. Additionally, given the ability of brown adipocytes to secrete soluble factors, which can promote angiogenesis (63) and rearrangement of the extracellular environment (64), BAs in the invasive front of breast tumors could enhance tumor growth indirectly by stimulating angiogenesis/remodeling of ECM as a consequence of promoting tumor cell invasion.

The main challenge for future studies will be to identify the pathway through which BAs regulate breast cancer development. Since tumor cells co-cultured with BAs exhibit an 
aggressive phenotype, we propose to evaluate the effect of BA-CM and BA-epithelial cells, in direct co-culture, on both morphological and metabolic changes, and activation of cancer stem cell signaling.

In conclusion, this study demonstrates that there are profound changes in protein expression and mitochondrial modifications during differentiation of 3T3-L1 preadipocytes into BAs, and that mitochondrial fission, which has been described in human brown adipose cells, also occurs in a mouse model (11). We propose that PPAR $\gamma$ activation of 3T3-L1 adipocytes could be an interesting model to study bidirectional communication between epithelial cells and BAs and how the latter participate in the development and progression of breast cancer.

Understanding the key signaling pathways in beige/brown adipose cells that might contribute to breast tumor progression will most certainly contribute to the development of novel therapeutic strategies to control breast tumor growth.

\section{Acknowledgements}

We acknowledge the technical assistance and support of Pablo Pomata for confocal microscopy observation. We thank Dr Lucrecia Piñeiro for her invaluable help in the correction of this manuscript.

\section{Funding}

We are gratefully thankful to Fundación Williams (Argentina) and Fundación Rene Barón (Argentina) for their support to IBYME (CONICET). This work was supported by CONICET grant BID PICT 2012-2489 and by a generous donation from Fundación Honorio Bigand, Buenos Aires, Argentina. PP, CL and GR are doctoral fellows, CONICET, Argentina.

\section{Availability of data and materials}

The datasets used during the present study are available from the corresponding author upon reasonable request.

\section{Authors' contributions}

MG designed and performed the experiments, analyzed the data and helped design the figures and write the manuscript. PP performed cell adhesion assays and Oil Red O staining and contributed to the data analyses. CL performed the western blot analysis and data analysis. GMR and MFR performed the RT-qPCR experiments and lactate measurement and data analysis. JCC contributed to the experimental design, helped edit and rewrite the manuscript and secured funding. JT conceived the hypothesis, designed, performed the experiments, and wrote the manuscript. All authors have read and approved the final version of the manuscript and agreed to be accountable for all aspects of the research, ensuring that the accuracy and integrity of any part of the work were suitably investigated and resolved.

\section{Ethics approval and consent to participate}

Not applicable.

\section{Patient consent for publication}

Not applicable.

\section{Competing interests}

The authors declare that they have no competing interests.

\section{References}

1. Peinado H, Zhang H, Matei IR, Costa-Silva B, Hoshino A, Rodrigues G, Psaila B, Kaplan RN, Bromberg JF, Kang Y, et al: Pre-metastatic niches: Organ-specific homes for metastases. Nat Rev Cancer 17: 302-317, 2017.

2. Dirat B, Bochet L, Dabek M, Daviaud D, Dauvillier S, Majed B, Wang YY, Meulle A, Salles B, Le Gonidec S, et al: Cancer-associated adipocytes exhibit an activated phenotype and contribute to breast cancer invasion. Cancer Res 71: 2455-2465, 2011.

3. Fletcher SJ, Sacca PA, Pistone-Creydt M, Coló FA, Serra MF, Santino FE, Sasso CV, Lopez-Fontana CM, Carón RW, Calvo JC and Pistone-Creydt V: Human breast adipose tissue: Characterization of factors that change during tumor progression in human breast cancer. J Exp Clin Cancer Res 36: 1-13, 2017.

4. Pistone Creydt V, Fletcher SJ, Giudice J, Bruzzone A, Chasseing NA, Gonzalez EG, Sacca PA and Calvo JC: Human adipose tissue from normal and tumoral breast regulates the behavior of mammary epithelial cells. Clin Transl Oncol 15: 124-131, 2013.

5. Wu Q, Li B, Li Z, Li J, Sun S and Sun S: Cancer-associated adipocytes: Key players in breast cancer progression. J Hematol Oncol 12: 95, 2019.

6. Pope BD, Warren CR, Parker KK and Cowan CA: Microenvironmental control of adipocyte fate and function. Trends Cell Biol 26: 745-755, 2016.

7. Park A: Distinction of white, beige and brown adipocytes derived from mesenchymal stem cells. World J Stem Cells 6: 33-42, 2014

8. Wang YY, Attané C, Milhas D, Dirat B, Dauvillier S, Guerard A, Gilhodes J, Lazar I, Alet N, Laurent V, et al: Mammary adipocytes stimulate breast cancer invasion through metabolic remodeling of tumor cells. JCI Insight 2: e87489, 2017.

9. Bussard KM, Mutkus L, Stumpf K, Gomez-Manzano C and Marini FC: Tumor-associated stromal cells as key contributors to the tumor microenvironment. Breast Cancer Res 18: 84, 2016.

10. Cannon B and Nedergaard J: Brown adipose tissue: Function and physiological significance. Physiol Rev 84: 277-359, 2004.

11. Sepa-Kishi DM and Ceddia RB: White and beige adipocytes: Are they metabolically distinct? Horm Mol Biol Clin Investig: 33, 2018 doi: 10.1515/hmbci-2018-0003.

12. Harms M and Seale P: Brown and beige fat: Development, function and therapeutic potential. Nat Med 19: 1252-1263, 2013.

13. Vitali A, Murano I, Zingaretti MC, Frontini A, Ricquier D and Cinti S: The adipose organ of obesity-prone $\mathrm{C} 57 \mathrm{BL} / 6 \mathrm{~J}$ mice is composed of mixed white and brown adipocytes. J Lipid Res 53: 619-629, 2012.

14. Master SR, Hartman JL, D'Cruz CM, Moody SE, Keiper EA, Ha SI, Cox JD, Belka GK and Chodosh LA: Functional microarray analysis of mammary organogenesis reveals a developmental role in adaptive thermogenesis. Mol Endocrinol 16: 1185-1203, 2002.

15. Gouon-Evans V and Pollard JW: Unexpected deposition of brown fat in mammary gland during postnatal development. Mol Endocrinol 16: 2618-2627, 2002.

16. Cao Q, Hersl J, La H, Smith M, Jenkins J, Goloubeva O, Dilsizian V, Tkaczuk K, Chen W and Jones L: A pilot study of FDG PET/CT detects a link between brown adipose tissue and breast cancer. BMC Cancer 14: 126, 2014.

17. Jones LP, Buelto D, Tago E and Owusu-Boaitey KE: Abnormal mammary adipose tissue environment of Brcal mutant mice show a persistent deposition of highly vascularized multilocular adipocytes. J Cancer Sci Ther 8 (Suppl 2): S4, 2011.

18. Singh R, Parveen M, Basgen JM, Fazel S, Meshesha MF, Thames EC, Moore B, Martinez L, Howard CB, Vergnes L, et al: Increased expression of beige/brown adipose markers from host and breast cancer cells influence xenograft formation in mice. Mol Cancer Res 14: 78-92, 2016. 
19. Wu Q, Li J, Li Z, Sun S, Zhu S, Wang L, Wu J, Yuan J, Zhang Y, Sun $S$ and Wang C: Exosomes from the tumour-adipocyte interplay stimulate beige/brown differentiation and reprogram metabolism in stromal adipocytes to promote tumour progression. J Exp Clin Cancer Res 38: 223, 2019.

20. Orava J, Nuutila P, Lidell ME, Oikonen V, Noponen T, Viljanen T, Scheinin M, Taittonen M, Niemi T, Enerbäck S and Virtanen KA: Different metabolic responses of human brown adipose tissue to activation by cold and insulin. Cell Metab 14: 272-279, 2011.

21. Wang F, Gao S, Chen F, Fu Z, Yin H, Lu X, Yu J and Lu C: Mammary fat of breast cancer: Gene expression profiling and functional characterization. PLoS One 9: e109742, 2014.

22. Urtreger A, Ladeda V, Puricelli L, Rivelli A, Vidal M, Delustig E and Joffe E: Modulation of fibronectin expression and proteolytic activity associated with the invasive and metastatic phenotype in two new murine mammary tumor cell lines. Int J Oncol 11: 489-496, 1997.

23. Lanari C, Lüthy I, Lamb CA, Fabris V, Pagano E, Helguero LA Sanjuan N, Merani $S$ and Molinolo AA: Five nove hormone-responsive cell lines derived from murine mammary ductal carcinomas: In vivo and in vitro effects of estrogens and progestins 1. Cancer Res 61: 293-302, 2001.

24. Creydt VP, Sacca PA, Tesone AJ, Vidal L and Calvo JC: Adipocyte differentiation influences the proliferation and migration of normal and tumoral breast epithelial cells. Mol Med Rep 3: 433-439, 2010.

25. Schmittgen TD and Livak KJ: Analyzing real-time PCR data by the comparative C(T) method. Nat Protoc 3: 1101-1108, 2008.

26. Kraus NA, Ehebauer F, Zapp B, Rudolphi B, Kraus BJ and Kraus D: Quantitative assessment of adipocyte differentiation in cell culture. Adipocyte 5: 351-358, 2016.

27. Wu J, Boström P, Sparks LM, Ye L, Choi JH, Giang AH, Khandekar M, Virtanen KA, Nuutila P, Schaart G, et al: Beige Adipocytes are a distinct type of thermogenic fat cell in mouse and human. Cell 150: 366-376, 2012.

28. Cohen AW, Razani B, Schubert W, Williams TM, Wang XB, Iyengar P, Brasaemle DL, Scherer PE and Lisanti MP: Role of caveolin-1 in the modulation of lipolysis and lipid droplet formation. Diabetes 53: 1261-1270, 2004.

29. Nieman KM, Kenny HA, Penicka CV, Ladanyi A, Buell-Gutbrod R, Zillhardt MR, Romero IL, Carey MS, Mills GB, Hotamisligil GS, et al: Adipocytes promote ovarian cancer metastasis and provide energy for rapid tumor growth. Nat Med 17: 1498-1503, 2011.

30. Bochet L, Lehuédé C, Dauvillier S, Wang YY, Dirat B, Laurent V, Dray C, Guiet R, Maridonneau-Parini I, Le Gonidec S, et al: Adipocyte-derived fibroblasts promote tumor progression and contribute to the desmoplastic reaction in breast cancer. Cancer Res 73: 5657-5668, 2013.

31. Lee J, Hong BS, Ryu HS, Lee HB, Lee M, Park IA, Kim J, Han W, Noh DY and Moon HG: Transition into inflammatory cancer associated adipocytes in breast cancer microenvironment requires microRNA regulatory mechanism. PLoS One 12: e0174126, 2017.

32. Muller C: Tumour-surrounding adipocytes are active players in breast cancer progression. Ann Endocrinol (Paris) 74: 108-110, 2013.

33. Cai J, Li B, Wang J, Liu K, Zhang Y, Liao Y and Lu F: Tamoxifen-prefabricated beige adipose tissue improves fat graft survival in mice. Plast Reconstr Surg 141: 930-940, 2018.

34. Petrovic N, Walden TB, Shabalina IG, Timmons JA, Cannon B and Nedergaard J: Chronic peroxisome proliferator-activated receptor gamma (PPARgamma) activation of epididymally derived white adipocyte cultures reveals a population of thermogenically competent, UCP1-containing adipocytes molecularly distinct from classic brown adipocytes. J Biol Chem 285 : 7153-7164, 2010

35. Cedikova M, Kripnerová M, Dvorakova J, Pitule P, Grundmanova M, Babuska V, Mullerova D and Kuncova J: Mitochondria in white, brown, and beige adipocytes. Stem Cells Int 2016: 6067349, 2016.

36. Pisani DF, Barquissau V, Chambard JC, Beuzelin D, Ghandour RA, Giroud M, Mairal A, Pagnotta S, Cinti S, Langin D and Amri EZ: Mitochondrial fission is associated with UCP1 activity in human brite/beige adipocytes. Mol Metab 7: 35-44, 2018

37. Wikstrom JD, Mahdaviani K, Liesa M, Sereda SB, Si Y, Las G, Twig G, Petrovic N, Zingaretti C, Graham A, et al: Hormone-induced mitochondrial fission is utilized by brown adipocytes as an amplification pathway for energy expenditure. EMBO J 33: 418-436, 2014
38. Wilson-Fritch L, Burkart A, Bell G, Mendelson K, Leszyk J, Nicoloro S, Czech M and Corvera S: Mitochondrial biogenesis and remodeling during adipogenesis and in response to the insulin sensitizer rosiglitazone. Mol Cell Biol 23: 1085-1094, 2003.

39. Castro É, Silva TEO and Festuccia T: Critical review of beige adipocyte thermogenic activation and contribution to whole-body energy expenditure. Horm Mol Biol Clin Investig: 31, 2017. doi: 10.1515/hmbci-2017-0042.

40. Ward PS and Thompson CB: Metabolic reprogramming: A cancer hallmark even warburg did not anticipate. Cancer Cell 21: 297-308, 2012.

41. Beloribi-Djefaflia S, Vasseur S and Guillaumond F: Lipid metabolic reprogramming in cancer cells. Oncogenesis 5: e189, 2016.

42. Wang Y, Tonouchi M, Miskovic D, Hatta H and Bonen A: T3 increases lactate transport and the expression of MCT4, but not MCT1, in rat skeletal muscle. Am J Physiol Endocrinol Metab 285: E622-E628, 2003.

43. Petersen C, Nielsen MD, Andersen ES, Basse AL, Isidor MS Markussen LK, Viuff BM, Lambert IH, Hansen JB and Pedersen SF: MCT1 and MCT4 expression and lactate flux activity increase during white and brown adipogenesis and impact adipocyte metabolism. Sci Rep 7: 13101, 2017.

44. Whitaker-Menezes D, Martinez-Outschoorn UE, Lin Z, Ertel A, Flomenberg N, Witkiewicz AK, Birbe RC, Howell A, Pavlides S, Gandara R, et al: Evidence for a stromal-epithelial 'Lactate Shuttle' in human tumors: MCT4 is a marker of oxidative stress in cancer-associated fibroblasts. Cell Cycle 10: 1772-1783, 2011

45. Li Z, Wu Q, Sun S, Wu J, Li J, Zhang Y, Wang C, Yuan J and Sun S: Monocarboxylate transporters in breast cancer and adipose tissue are novel biomarkers and potential therapeutic targets. Biochem Biophys Res Commun 501: 962-967, 2018.

46. Liberti MV and Locasale JW: The warburg effect: How does it benefit cancer cells? Trends Biochem Sci 41: 211-218, 2016.

47. Pavlides S, Whitaker-Menezes D, Castello-Cros R, Flomenberg N, Witkiewicz AK, Frank PG, Casimiro MC, Wang C, Fortina P, Addya S, et al: The reverse warburg effect: Aerobic glycolysis in cancer associated fibroblasts and the tumor stroma. Cell Cycle 8: 3984-4001, 2009.

48. Schäffler A, Schölmerich J and Buechler C: Mechanisms of disease: Adipokines and breast cancer-endocrine and paracrine mechanisms that connect adiposity and breast cancer. Nat Clin Pract Endocrinol Metab 3: 345-354, 2007.

49. Choi J, Cha YJ and Koo JS: Adipocyte biology in breast cancer: From silent bystander to active facilitator. Prog Lipid Res 69: $11-20,2018$

50. Gnerlich JL, Yao KA, Fitchev PS, Goldschmidt RA, Bond MC, Cornwell $\mathrm{M}$ and Crawford SE: Peritumoral expression of adipokines and fatty acids in breast cancer. Ann Surg Oncol 20 (Suppl 3): S731-S738, 2013.

51. Ertunc ME, Sikkeland J, Fenaroli F, Griffiths G, Daniels MP, Cao H, Saatcioglu F and Hotamisligil GS: Secretion of fatty acid binding protein aP2 from adipocytes through a nonclassical pathway in response to adipocyte lipase activity. J Lipid Res 56: 423-434, 2015

52. Hotamisligil GS and Bernlohr DA: Metabolic functions of FABPs-mechanisms and therapeutic implications. Nat Rev Endocrinol 11: 592-605, 2015.

53. Guaita-Esteruelas S, Bosquet A, Saavedra $\mathrm{P}$, Gumà J, Girona J, Lam EW, Amillano K, Borràs $\mathrm{J}$ and Masana L: Exogenous FABP4 increases breast cancer cell proliferation and activates the expression of fatty acid transport proteins. Mol Carcinog 56: 208-217, 2017.

54. Guaita-Esteruelas S, Saavedra-García P, Bosquet A, Borràs J, Girona J, Amiliano K, Rodríguez-Balada M, Heras M, Masana L and Gumà $\mathrm{J}$ : Adipose-derived fatty acid-binding proteins plasma concentrations are increased in breast cancer patients. Oncologist 22: 1309-1315, 2017.

55. Witkiewicz AK, Kline J, Queenan M, Brody JR, Tsirigos A, Bilal E, Pavlides S, Ertel A, Sotgia F and Lisanti MP: Molecular profiling of a lethal tumor microenvironment, as defined by stromal caveolin-1 status in breast cancers. Cell Cycle 10: 1794-1809, 2011.

56. Wang P, Renes J, Bouwman F, Bunschoten A, Mariman E and Keijer J: Absence of an adipogenic effect of rosiglitazone on mature 3T3-L1 adipocytes: Increase of lipid catabolism and reduction of adipokine expression. Diabetologia 50: 654-665, 2007. 
57. Sanchez-Alvarez R, Martinez-Outschoorn UE, Lamb R, Hulit J, Howell A, Gandara R, Sartini M, Rubin E, Lisanti MP and Sotgia F: Mitochondrial dysfunction in breast cancer cells prevents tumor growth: Understanding chemoprevention with metformin. Cell Cycle 12: 172-182, 2013.

58. Martinez-Outschoorn U, Sotgia F and Lisanti MP: Tumor microenvironment and metabolic synergy in breast cancers: Critical importance of mitochondrial fuels and function. Semin Oncol 41: 195-216, 2014.

59. Huang CK, Chang PH, Kuo WH, Chen CL, Jeng YM, Chang KJ, Shew JY, Hu CM and Lee WH: Adipocytes promote malignant growth of breast tumours with monocarboxylate transporter 2 expression via $\beta$-hydroxybutyrate. Nat Commun 8: 14706, 2017.

60. Köhrmann A, Kammerer U, Kapp M, Dietl J and Anacker J: Expression of matrix metalloproteinases (MMPs) in primary human breast cancer and breast cancer cell lines: New findings and review of the literature. BMC Cancer 9: 188, 2009.
61. Iida J, Clancy R, Dorchak J, Somiari RI, Somiari S, Cutler ML, Mural RJ and Shriver CD: DNA aptamers against exon v10 of CD44 inhibit breast cancer cell migration. PLoS One 9: e88712, 2014.

62. Nam KS, Oh S, Lee KM, Yoo SA and Shin I: CD44 regulates cell proliferation, migration, and invasion via modulation of c-Src transcription in human breast cancer cells. Cell Signal 27: 1882-1894, 2015

63. Villarroya F, Cereijo R, Villarroya J and Giralt M: Brown adipose tissue as a secretory organ. Nat Rev Endocrinol 13: 26-35, 2017.

64. Chen SQ, Niu Q, Ju LP, Alimujiang M, Yan H, Bai NN, Xu J, Fang QC, Han JF, Yang Y and Jia WP: Predicted secreted protein analysis reveals synaptogenic function of Clstn3 during WAT browning and BAT activation in mice. Acta Pharmacol Sin 40: 999-1009, 2019. 